\title{
Is older adult care mediated by caregivers' cultural stereotypes? The role of competence and warmth attribution
}

\author{
Rocío Fernández- \\ Ballesteros' \\ Antonio Bustillos ${ }^{2}$ \\ Marta Santacreu ${ }^{1,3}$ \\ Rocio Schettini' \\ Pura Díaz-Veiga ${ }^{4}$ \\ Carmen Huici ${ }^{2}$ \\ 'Clinical and Health Psychology, \\ Universidad Autónoma de Madrid \\ (UAM), ${ }^{2}$ Social Psychology, \\ Universidad Nacional de Educación \\ a Distancia (UNED), ${ }^{3}$ Psychology \\ Department, Universidad Europea \\ de Madrid (UEM), ${ }^{4}$ Matia Instituto \\ Gerontológico, Madrid, Spain
}

\author{
This article was published in the following Dove Press journal: \\ Clinical Interventions in Aging \\ 5 May 2016 \\ Number of times this article has been viewed
}

Purpose: The purpose of this study is to examine, from the stereotype content model (SCM) perspective, the role of the competence and warmth stereotypes of older adults held by professional caregivers.

Methods: A quasi-experimental design, ex post facto with observational analyses, was used in this study. The cultural view on competence and warmth was assessed in 100 caregivers working in a set of six residential geriatric care units (three of them organized following a person-centered care approach and the other three providing standard geriatric care). In order to assess caregivers' cultural stereotypical views, the SCM questionnaire was administered. To evaluate the role of caregivers' cultural stereotypes in their professional performance as well as in older adult functioning, two observational scales from the Sistema de Evaluación de Residencias de Ancianos (assessment system for older adults residences)-RS (staff functioning and residents' functioning) were applied.

Results: Caregivers' cultural views of older adults (compared to young people) are characterized by low competence and high warmth, replicating the data obtained elsewhere from the SCM. Most importantly, the person-centered units predict better staff performance and better resident functioning than standard units. Moreover, cultural stereotyping of older adult competence moderates the effects of staff performance on resident functioning, in line with the findings of previous research.

Conclusion: Our results underline the influence of caregivers' cultural stereotypes on the type of care, as well as on their professional behaviors and on older adult functioning. Caregivers' cultural stereotypes could be considered as a central issue in older adult care since they mediate the triangle of care: caregivers/older adults/type of care; therefore, much more attention should be paid to this psychosocial care component.

Keywords: cultural stereotypes, caregiver functioning, older adult functioning, person-centered care vs standard care, stereotype content model

\section{Introduction}

The stereotype content model $(\mathrm{SCM})^{1}$ posits that cultural stereotypes can be grouped into two basic dimensions of social perception: warmth and competence. Different clusters of high vs low warmth and competence cultural stereotypes were tested by Cuddy et al across widely varied target groups, from national and ethnic to age and sex. ${ }^{1}$ Moreover, these patterns appeared to be universal in USA and in 17 other nations.

Age is one of the primary characteristics of interpersonal categorization, as are sex and ethnicity, ${ }^{2-5}$ but it is a physical and objective attribute of the individual measured across the lifespan as years lived. In fact, however, it is not age, but rather the process of aging associated with decline, illness, and death that is the central dimension for
Correspondence: Rocío FernándezBallesteros

Universidad Autónoma de Madrid (UAM), C/Ivan Pavlov, 6, Ciudad Universitaria de Cantoblanco, Madrid 28049, Spain

Tel +34 9l 4975181

Email r.fballesteros@uam.es
Clinical Interventions in Aging 20 I 6: I I 545-552

545

Dovepress

http://dx.doi.org/10.2147/CIA.S96235 (c) (1) (9) 2016 Fernández-Ballesteros et al. This work is published and licensed by Dove Medical Press Limited. The full terms of this license are available at https://www.dovepress.com/terms.php hereby accept the Terms. Non-commercial uses of the work are permitted without any further permission from Dove Medical Press Limited, provided the work is properly attributed. For permission hereby accept the Terms. Non-commercial uses of the work are permitted without any further permission from Dove M
for commercial use of this work, please see paragraphs 4.2 and 5 of our Terms (https://www.dovepress.com/terms.php). 
negative aging stereotyping as well as for the prejudice and discrimination to which older adults are subjected in most societies. $^{6,7}$

In spite of the variability in the forms of aging - through a mechanism of generalization based on pathologicalaging-older adults, as a group, are stereotyped as low-competence (LC)/ high warmth (HW), in the same way as people with disabilities or developmental disorders. From the SCM, the combination of these two social stereotypes, LC and HW, is considered as a paternalism pattern found cross-culturally. ${ }^{1,8,9}$ It must be emphasized that because most of the empirical studies providing information on this important issue have been carried out with students and/or the general population from various countries and cultures, there is a lack of data on older adult caregivers.

Aging stereotypes also influence older adult functioning. Thus, $>30$ years ago, Rodin and Langer ${ }^{10}$ tested the hypothesis that some older adult behaviors attributed to the process of aging (such as low self-esteem and control) are the result of self-classification, producing ageist self-fulfilling prophecies. Much more recently, Langer in her book Counter Clockwise discussed a quasi-natural experiment in which older adults were placed in a younger situation, showing the importance of group stereotype and self-expectation for improved health and cognitive functioning and age-related decline. ${ }^{11}$ Along similar lines, findings from Levy ${ }^{12,13}$ support the assumption that perceived stereotypes generate expectations, which, in turn, are more likely to act as self-fulfilling and/or otherfulfilling prophecies when there is a correspondence between the stereotypes and personal outcomes.

In the previous studies, it was tested whether cultural stereotypes reported by professional caregivers had an effect on their caring behaviors as well as on the functioning of older adults. ${ }^{14,15}$ In sum, better quality of caregiver performance was associated with better older adult functioning; moreover, this positive relationship partially depends on caregivers. Older adults' functioning was positively influenced at the centers where caregivers held less stereotypical views of them; at the centers in which caregivers reported a more positive view of competence, elders' functioning was much better. Although these results are congruent with our hypothesis regarding the effect of caregivers' cultural stereotypes on their care behaviors, it could also be explained as a kind of older adults' self-fulfilling prophecy. ${ }^{16}$

Traditionally, professionals in long-term care facilities are developing top-down care tasks that could nowadays be considered as standard care (SC). Several factors inform the need to go beyond top-down task-centered care: 1) baby boomers becoming older and asking for new ways of being cared for and 2) the increase in life expectancy together with the proliferation of chronic illnesses requiring long-term care based on a biopsychosocial approach, responding to new needs and demands. ${ }^{17,18}$ Person-centered care (PCC) has appeared as an alternative approach to $\mathrm{SC}$; this concept is based on the premise that older person functioning is not just the result of changes caused by old age or a given illness but a consequence of a complex interaction between the person's characteristics and their psychosocial environment. Thus, PCC is focused on changing how care is delivered (eg, training caregivers) and where care is provided (eg, making structural and esthetic changes in the facility). Regarding the former, Carl Rogers, the founder of the person-centered approach to care, proposed that care tasks should be based on acceptance, caring, empathy, sensitivity, and active listening in order to promote optimal human growth. ${ }^{17,18}$ On the other hand, William Thomas, the promoter of The Eden Alternative, highlighted the need to deinstitutionalize aged-care facilities by refreshing the environment to create a warm atmosphere reminiscent of home that enriches the lives of all who live and work in it. ${ }^{17,19}$

Studies have shown positive effects of PCC compared to SC on different outcomes not only among residents (a decrease in the use of chemical restraints, less resident agitation and aggression, fewer falls, higher quality of life, and an increase in residents' participation) but also for the professional caregivers. ${ }^{18-20}$

Given the support that the influence of aging stereotypes on caregivers' and care recipients' behavior has received, it is predicted that PCC will show differences in caregivers' stereotypes and professional behaviors when compared to $\mathrm{SC}$, and furthermore, that competence cultural stereotype mediates in care recipients, as suggested by Bustillos and Fernández-Ballesteros ${ }^{14,15}$ and Knight et al. ${ }^{21}$

\section{Objectives}

To ascertain to what extent older adult's caregivers have a cultural view on aging as HW/LC similar to other general populations; and to discover the extent to which this stereotypical profile plays a mediating role between caregivers' professional care and older adult functioning in two types of care, PCC and SC.

\section{Methods \\ Design}

The study was approved by the Autonoma University Ethics Committee. Written informed consent was provided by all participants. Following Campbell and Stanley, ${ }^{22}$ a quasi-experimental design, ex post facto analyses, has been followed. 


\section{PCC and SC}

Six units within nursing homes providing services to dependent older adults in the Basque Country (Spain) participated in this study. Three of them were PCC units and the other three were SC units. Each PCC and SC unit provided care for 13-14 residents and employed 13-21 professional caregivers (including nurses, physiotherapists, social workers, and caregivers).

A description of the two types of care (PCC and SC) is as follows:

- PCC: the main objective is to make the nursing home unit as similar as possible to the old person's own home following the need and preferences of residents. Physical and organizational changes facilitate behavioral interactions between caregivers and residents and maximize residents' independence and autonomy. Such changes have previously been discussed by Díaz-Veiga et al. The interventions were implemented in three units located in three different nursing homes belonging to the Matias Foundation..$^{20}$

- SC: the other three units were selected from nursing homes providing $\mathrm{SC}$ and have similar numbers of residents and caregivers as PCC units.

Regarding professional caregivers, the sample comprised 100 participants ( $91 \%$ women) aged between 20 years and 58 years (mean $\bar{x}=38.73, \mathrm{SD}=9.04$ ). The number of caregivers in each unit ranged from ten to 22 .

\section{Measures}

The SCM questionnaire ${ }^{9}$ was anonymously administered to all caregivers in the six nursing homes, providing the following instructions: In the following questionnaire, a series of characteristics that define people are shown. We are not interested in your personal opinion; we are only interested in the extent to which you think that, in Spain, these characteristics are used to define younger and older adults. Response format was Likert-type ranging from 1 (does not describe them at all) to 7 (describes them very well). Both scales yielded adequate reliability statistics: $\alpha=0.85$ for the competence scale and $\alpha=0.77$ for the warmth scale. In order to consider the stereotypical pattern $\mathrm{LC} / \mathrm{HW}$, following Fiske et al, ${ }^{9}$ the mean values of competence and warmth were compared in both older and younger adults' groups.

Two subscales of the evaluation scale from the Sistema de Evaluación de Residencias de Ancianos (SERA)-RS ${ }^{23}$ based on the multiphasic environmental assessment procedure (MEAP) by Moos and Lemke ${ }^{24}$ were administered:

- Resident functioning: this subscale has five dimensions: personal grooming, condition of clothing, residents' interaction, brief verbal exchanges, and general amount of activity. Response options range from 0 to 3 (giving observable examples for each options range), with higher scores indicating better resident functioning.

- Staff functioning: from this scale, five dimensions assessing caregivers' professional behaviors were selected: quality of interaction, physical contact with residents, organization, staff availability for residents, and staff conflict (eg, Do staff have physical contact with residents? and, What is the degree of the staff's availability for residents?). Response options range from 0 to 3 (giving observable examples for each option range), with higher scores indicating better staff functioning.

\section{Observational procedure}

Two independently trained raters observed each residential home twice a day (morning and afternoon) for 30 minutes per session; ratings were made after the observation period. This allowed for the counterbalancing of time of day, times, and observers. In addition, we recorded temporal reliability and interobserver reliability. During each observation, only the behavior of the caregivers who were working at the time of the observation was registered, that is, the behavioral records do not cover all the caregivers who completed the questionnaires.

Although both SERA and MEAP manuals state high interobserver agreements, in this study, we proceed to estimate interobserver agreement through two procedures: intraobserver reliability between two temporal observations (Cronbach's $\alpha$ ) and intraclass correlation coefficients (ICCs). The resident functioning scale showed a good internal consistency $(\alpha=0.83)$ and an adequate ICC $(0.76)$. For the staff functioning scale, Cronbach's $\alpha$ was also adequate $(0.84)$, as was the ICC (0.69). ${ }^{25}$

As has been mentioned earlier, observations on caregivers and resident functioning were made by trained reviewers who were not aware of the type of care provided.

\section{Results PCC vs SC}

First, in order to evaluate the extent to which PCC and SC approaches changed staff and resident functioning, Student's $t$-tests were performed. This analysis was carried out on the 24 observations made by the two observers and indicated the effect of the type of care on staff functioning, $t(22)=3.93$, $P<0.001$. Staff in the PCC units showed better functioning $(\overline{\mathrm{x}}=2.53, \mathrm{SD}=0.64)$ than staff in SC units $(\overline{\mathrm{x}}=1.67, \mathrm{SD}=0.40)$. A statistically significant difference was also found for resident functioning, $t(22)=3.95, P<0.001$. Residents in the 
PCC units showed a better functioning $(\overline{\mathrm{x}}=1.90, \mathrm{SD}=0.53)$ than those in the SC units ( $\overline{\mathrm{x}}=1.15, \mathrm{SD}=0.39)$. That is, PCC seems to affect positively both staff functioning and older adult functioning compared to the SC units. Correlational analysis indicates that staff and resident functioning were highly associated ( $r=0.64, P<0.001)$.

Second, in order to check whether PCC affects resident behavior through staff functioning, mediational analyses were used. The type of care was dummy-coded, so that SC units were coded with 0 , and PCC units were coded with 1 . First, this analysis indicated that the PCC condition affected staff functioning $(\beta=0.87, t=11.85, P<0.0001)$ and resident functioning $(\beta=0.66, t=11.88, P<0.0001)$. Second, staff functioning significantly predicts resident functioning ( $\beta=0.55, t=10.77, P<0.0001)$. When PCC and staff functioning were taken into account in the prediction of resident functioning, the PCC intervention showed a significant effect ( $\beta=0.42, t=5.22, P<0.0001)$; this also applied to staff functioning $(\beta=0.27, t=3.76, P<0.001)$. A Sobel test indicated that indirect effects of intervention through staff functioning on resident functioning were significant $(Z=3.58, P<0.0005)$. These data are shown in Figure 1.

\section{SCM and the mediated moderation effect of the competence dimension}

We first tested whether the SCM is replicated in this sample by analyzing the individual responses of 100 staff caregivers in both PCC and SC settings. In line with the previous study, a repeated-measures Multivariate analysis of variance (MANOVA) $(2 \times 2)$ was carried out in which the first factor was perceived as the levels of competence and warmth, or stereotype dimensions, and the second factor was the group to which they were attributed (young people vs older adults). A significant effect of the first factor was found, $F(1.99)=12.70$, $P<0.001, \eta^{2}=0.11$; in general, participants attributed more traits of competence $(\overline{\mathrm{x}}=4.77, \mathrm{SD}=0.95)$ than warmth $(\overline{\mathrm{x}}=4.53$,

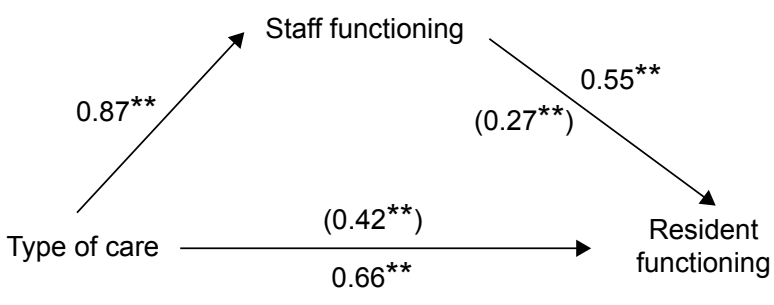

Figure I Results of the hypothesized mediational model with staff behavior as mediator between type of care and resident behavior.

Notes: Partial regression coefficients are presented in parentheses. The number in parentheses indicates the direct effects after controlling the effects of the two predictors. Type of care was dummy coded: 0, SC units; I, PCC units. $* * P<0.01$. Abbreviations: PCC, person-centered care; SC, standard care.
$\mathrm{SD}=1.01)$. In addition, we found an effect of the group to which the stereotype refers: more stereotypical traits are attributed to young people $(\overline{\mathrm{x}}=4.94, \mathrm{SD}=0.95)$ than to older adults $(\overline{\mathrm{x}}=4.36, \mathrm{SD}=1.00), F(1,99)=27.21, P<0.0001, \eta^{2}=0.22$. More important was the effect of the interaction between the two stereotypical dimensions with reference to young people and older adults $F(1,99)=98.84, P<0.0001, \eta^{2}=0.50$.

As shown in Figure 2, testing for the difference of means by applying the Bonferroni correction indicated that young people were perceived as more competent $(\overline{\mathrm{x}}=5.19$, $\mathrm{SD}=0.97)$ than warm $(\overline{\mathrm{x}}=3.87, \mathrm{SD}=0.93), D_{i-j}=0.51$, $P<0.0001$, while older adults were perceived warm $(\overline{\mathrm{x}}=4.86$, $\mathrm{SD}=0.96)$ rather than competent $(\overline{\mathrm{x}}=3.86, \mathrm{SD}=1.04)$, $D_{i-j}=0.99, P<0.0001$. In other words, the SCM is replicated in this sample.

MANOVAs were performed with nursing homes, which were considered as a between-subjects factor. The results indicate no interaction effects of the institution $F(5,94)=0.64$, nonsignificant (ns).

Finally, we tested whether the competence and warmth dimensions referring to older adults are affected by the type of care. No effect was found for either the competence dimension $t=0.43$, ns or the warmth dimension, $t=0.00$, ns.

In order to check whether the perceived cultural stereotypes of competence and warmth moderated the effects of the staff functioning on resident functioning, competence and warmth scores were introduced in the analysis as individual measures and the observed behavior of staff and residents as group measures. These latter variables were computed from the mean of the observed behaviors for the six residential homes, which was obtained from two observers at two different times. We employed the PROCESS procedure by Hayes for each of the SCM dimensions. ${ }^{26}$ The model tested takes into account that the type of care (independent variable [IV]) predicts staff behavior (moderator variable [M]) and residents' behavior (dependent variable [DV]). Staff behavior (M) predicts residents' behavior, but this relationship is affected by the SCM competence dimension and not by the warmth dimension. This kind of model is called second stage moderation model by Hayes and Edwards and Lambert in which a variable affects the relationship between mediator (staff functioning) and DV (resident functioning) but does not affect the relationship between predictor (type of care) and dependent variable. ${ }^{26,27}$ We chose this model because previous Student's $t$-tests indicate that the type of case does not affect the stereotypical dimensions of competence and warmth.

The analysis that takes into account the competence dimension as moderator of the relationship between staff and 


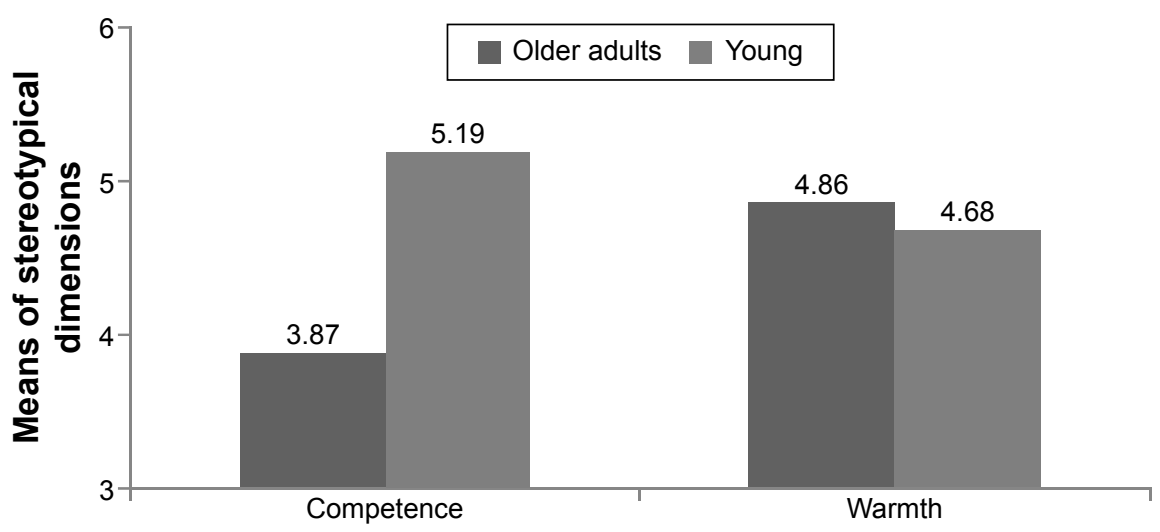

Figure 2 Means of competence and warmth for older adults and young people.

resident functioning shows a good fit of the model to the data $\left(R^{2}=0.66, F=46.80, P<0.0001\right)$. The PCC type of care shows a significant effect on resident functioning $(\beta=0.43, t=5.36$, $P<0.0001$ ), similar to that found in the previous mediational analysis where staff functioning controls the effect of the experimental treatment (Figure 3). The competence dimension also has a significant effect on resident functioning ( $\beta=-0.25, t=2.42, P<0.02$ ). Staff functioning does not show significant effects on resident functioning ( $\beta=-0.21$, $t=1.01$, ns), but an interaction effect emerged between staff functioning and attribution of competence to older adults ( $\beta=0.12, t=2.40, P<0.02$ ). In other words, cultural perception of older adult competence is not affected by the type of care but moderates the effects of staff functioning on resident functioning. These data are shown in Figure 3.

In order to test the indirect effects of the types of care on resident functioning, these effects were estimated by employing a bootstrapping on 1,000 subsamples. As shown in Table 1, the indirect effect of staff functioning on resident functioning was significant because with a $95 \%$ confidence interval these effects were not zero. Furthermore, the effect of staff behavior on resident functioning was greater when scores on the competence dimension are higher (percentiles 50th, 75th, and 90th). In other words, there is an indirect effect of the type of care on resident functioning through staff functioning, that is, the positive relationship between staff functioning and resident functioning is enhanced when the staff hold a cultural stereotype perception of older adults, which attributes to them higher levels of competence.

An analysis that takes into account the warmth dimension indicates that the model shows a poorer fit to the data than the previous model $\left(R^{2}=0.64, F=46.80, P<0.0001\right)$ and also shows that PCC has a significant effect on resident functioning ( $\beta=0.43, t=5.28, P<0.0001$ ). However, the warmth dimension does not exhibit a significant effect on resident functioning $(\beta=-0.11, t=0.24, \mathrm{~ns})$, and staff functioning does not affect resident functioning $(\beta=0.06, t=0.25$, ns); nor was an interaction effect found between staff functioning and the warmth dimension $(\beta=0.04, t=0.80$, ns $)$.

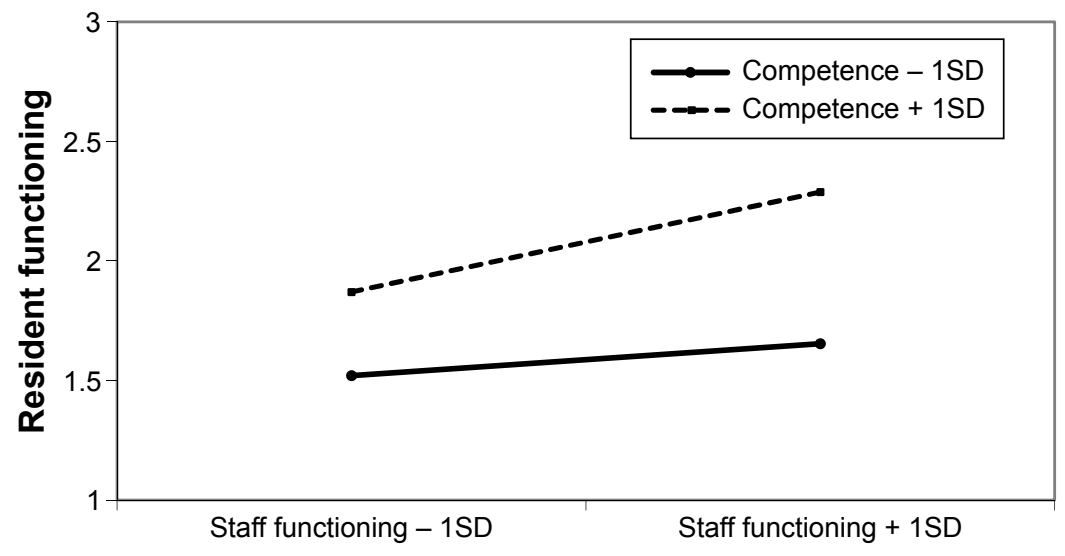

Figure 3 Moderation effect of the competence dimension and staff functioning on resident functioning. Abbreviation: SD, standard deviation. 
Table I lindirect effect of staff functioning on resident functioning at values of moderator competence

\begin{tabular}{lllll}
\hline Competence & Effect & SE & \multicolumn{2}{l}{$95 \% \mathbf{C l}$} \\
\cline { 4 - 5 } & & & LL & UL \\
\hline 10th & 0.06 & 0.10 & -0.14 & 0.27 \\
25th & 0.14 & 0.08 & -0.01 & 0.31 \\
50 th & 0.23 & 0.08 & 0.08 & 0.38 \\
75th & 0.31 & 0.08 & 0.14 & 0.48 \\
90th & 0.33 & 0.09 & 0.15 & 0.50 \\
\hline
\end{tabular}

Note: Values for moderator are 10th, 25th, 50th, 75th, and 90th percentiles of the distribution in the sample.

Abbreviations: $\mathrm{Cl}$, confidence interval; LL, lower limit; SE, standard error; UL, upper limit.

\section{Discussion}

Caregivers in residential settings hold cultural views about older adults, attributing to them LC and HW (in contrast to young people who are perceived as high competence and low warmth). These results replicate the data obtained by Cuddy et $\mathrm{al}^{28}$ with college student samples from seven different countries (USA, Belgium, Costa Rica, South Korea, Hong Kong, Japan, and Israel), those obtained by our research group based on a representative sample of the Spanish population aged $>18$ years, as well as a sample of geriatricians and gerontologists, ${ }^{29}$ and those obtained by Bustillos and Fernandez-Ballesteros with a Mexican sample of older adult caregivers. ${ }^{15}$ Moreover, our sample of caregivers showed a profile that was less stereotypical than that reported by Fiske et al: older adult competence $=2.74$ and warmth $=4.06$ contrasting with, respectively, 3.78 and $4.86 .{ }^{9}$ Finally, supporting the validity of this view, no significant differences were found between geriatricians and gerontologists working in different professional contexts regarding stereotypical perception as reported by Fernández-Ballesteros et al. ${ }^{29}$

Furthermore, after evaluating the extent to which caregivers hold the stereotypical pattern LC/HW, we proceeded to evaluate the types of care, observing caregiver behaviors and resident functioning. Our prediction is that both staff behaviors and resident functioning will be significantly better in the PCC units than in the SC units; on comparing them, our evaluation results showed that both the staff's professional functioning and resident functioning are significantly better in the PCC units than in the SC units. Moreover, correlation analysis indicates that staff and resident functioning were strongly associated, that is, good staff functioning was related to good resident functioning. These results are in line with those reported by FernándezBallesteros with a Spanish sample of residential settings for older adults and also by Moos and Lemke in US residential facilities. ${ }^{23,24,30}$ The results are also supported by evidence showing the importance of caregivers' decisions in care recipients' functioning. ${ }^{21}$

But what role do caregivers' stereotypical cultural views of older adults (such as LC and HW) play both in their own behavior and in residents' functioning? In order to check whether a perceived cultural stereotype of competence and warmth moderates the effects of staff functioning on resident functioning in our residential homes, ${ }^{15}$ competence and warmth scores were introduced in the analysis as individual measures, and observed behavior of staff and residents as group measures. These latter variables were computed from the mean (observations by institution) of the observed behaviors for each home, which was obtained by two observers at two different times. The model tested takes into account that the type of care, especially PCC vs SC, predicts staff behavior and resident functioning. Staff behavior predicts resident behavior, although this relationship is affected by the competence dimension but not the warmth dimension of the stereotype described in the SCM. This result is in line with those obtained by Bustillos and Fernández-Ballesteros ${ }^{15}$ and supports the hypothesis that other people's negative perceptions about competence of aging may act as a self-fulfilling prophecy. ${ }^{10,12,16}$

The analysis that takes into account the competence dimension as a moderator of the relationship between staff and resident functioning shows a good fit to the data. The type of care, that is, PCC vs SC, shows a significant effect on resident functioning. The competence dimension also has a significant effect on resident functioning, and an interaction effect emerged between staff functioning and attribution of competence to older adults. In other words, the cultural perception of older adult competence moderates the effects of staff functioning on resident functioning.

In summary, the nursing home caregivers assessed report cultural stereotyping in accordance with the SCM model: older adults are perceived as LC and HW, replicating the so-called paternalistic prejudice. Moreover, in-line with the theoretical background and our own empirical research, ${ }^{15,27}$ it has been predicted that caregiver's stereotyping exerts an influence on both caregiver behaviors and resident functioning. Thus, our results support a mediating role of caregiver stereotyping in both types of functioning. In fact, in those units in which caregivers reported more competence, caregivers behaved more positively, and residents showed better functioning; thus, our results are in accordance with our prediction. Nevertheless, several theoretical and methodological questions remain unanswered. 
Caregivers' cultural stereotypical perception of competence predicts their positive behaviors (eg, physical contact with residents and high degree of staff availability for residents), as well as residents' good functioning (eg, strong interactions between them and good appearance) ("Methods" section). It must be stressed that, from the SCM, cultural stereotyping as $\mathrm{LC}$ and $\mathrm{HW}$ is considered as a paternalistic prejudice; however, we are not considering here whether caregiver behaviors are paternalistic for the simple reason that we assessed not paternalism but the staff's views of older adults as professional functioning in general. In fact, paternalism has not been operationally defined (in behavioral terms) by the SCM model. It must be emphasized that our observations did not cover those constructs.

In our opinion, when the role of LC and HW cultural stereotype perceived by caregivers is investigated, paternalistic behavioral data must be examined close to the ground, which in relation to our data means mediation between staff behavior and resident functioning. Nevertheless, our results show that cultural stereotyping of older adult competence is a key aspect in the planning and implementation of interventions to improve older adult functioning. As the WHO underlines, ${ }^{16}$ caregivers may be aware of cultural images on older adults, and there is a possibility that what they have in mind can become a self-fulfilling prophecy; ${ }^{31}$ in fact, caregivers in our study who perceive higher cultural competence in the functioning of older adult residents (75th percentile and higher) did a better job (Table 1). These results are in agreement with those yielded by our previous research in which 74 caregivers working in all geriatric residences, day care, and senior centers were assessed with the same instruments and procedures as in this study. ${ }^{14,15}$ Results showed that stereotypical beliefs about competence (but not warmth) mediated the relationships between professional behaviors of caregivers and older adult functioning. Thus, in a context of caregiving, competence perception may be important for improving both caregiver and older adult functioning.

This study has several limitations. First of all, it is extremely difficult to characterize one of our dependent variables, type of care, because both PCC and SC have myriad sources of variation. Similarly, professional and resident functioning also have sources of differences; since our purpose was to select overt behaviors, observational scales required that these two important dependent variables be reduced to the items present in the SERA/MEAP rating scales. In order to generalize our results, other measures must be introduced. Furthermore, in order to clarify paternalistic prejudice as an effect of cultural stereotyping of LC and HW, observational measures of paternalism must be developed and implemented at the same time as other behavioral measures of caregivers and older adult residents. Finally, we continue to work on how to change cultural and group stereotyping and self-perception of aging, ${ }^{32}$ trying especially to change caregivers' cultural view of incompetence in older adults. In summary, much more research is needed in order to support policy actions against cultural stereotyping, but in any case, this issue can be considered as a neglected aspect within the field of older adult care.

\section{Acknowledgments}

This study was supported by the EVE Project (Aging stereotypes: associations, effects and actions; Estereotipos sobre la vejez: asociaciones, efectos y actuaciones) and PSI 2010-1770 by the Science and Innovation Ministry of Spain. Principal Investigator: Dr Rocío Fernández-Ballesteros.

\section{Disclosure}

The authors report no conflicts of interest in this work.

\section{References}

1. Cuddy AJC, Fiske ST, Glick P. Warmth and competence as universal dimensions of social perception: the stereotype content model and the BIAS map. Adv Exp Soc Psychol. 2008;40:61-149.

2. Fiske ST. Stereotyping, prejudice, and discrimination. In: Gilbert DT, Fiske ST, Lindzey G, editors. The Handbook of Social Psychology. 4th ed. New York: McGraw-Hill; 1998:357-411.

3. Haslam C, Morton TA, Haslam SA, et al. When the age is in, the wit is out: age-related self-classification on deficit expectations reduce performance on clinical tests used in dementia assessment. Psychol Aging. 2012;27:778-784.

4. Kite ME, Deaux K, Miele M. Stereotypes of young and old: does age outweigh gender? Psychol Aging. 1991;6:19-27.

5. Kunda Z. Social Cognition. Cambridge, MA: MIT Press; 1999.

6. Fernández-Ballesteros R, Bustillos A, Huici C, et al. Age discrimination, Eppur si muove (and yet it moves). J Am Geriatr Soc. 2015;(2):453-455.

7. North MS, Fiske ST. An inconvenienced youth? Ageism and its potential intergenerational roots. Psychol Bull. 2013;138(5):982-997.

8. Caprariello PA, Cuddy AJC, Fiske ST. Social structure shapes cultural stereotypes and emotions. A causal test of the stereotype content model. Group Process Intergroup Relat. 2009;12:147-155.

9. Fiske ST, Cuddy AC, Glick P, et al. A model of often mixed stereotype content: competence and warmth respectively follow from perceived status and competition. J Pers Soc Psychol. 2002;82:878-902.

10. Rodin J, Langer E. Aging labels: the decline of control and the fall of self-esteem. J Soc Issues. 1980;36:12-29.

11. Langer EJ. Counter Clockwise: Mindfulhealth and the Power of Possibility. New York: Ballantine books; 2009.

12. Levy BR. Mind matters: cognitive and physical effects of ageing selfstereotypes. J Gerontol B Psychol Sci Soc Sci. 2003;58B(4):203-211.

13. Levy BR. Stereotype embodiment a psychosocial approach to ageing. Curr Dir Psychol Sci. 2009;18:332-336.

14. Bustillos A, Fernández-Ballesteros R. Efecto de los estereotipos acerca de la vejez en la atención a adultos mayores [Effect of stereotypes about old age in the care of older adults]. Salud Pública Mex. 2012; 54:104-105.

15. Bustillos A, Fernández-Ballesteros R. Attributions of competence mediate the behaviors of caregivers and older adults. GeroPsych. $2013 ; 26: 1-7$. 
16. World Health Organizations. Healthy Ageing. Geneva: WHO; 1990.

17. Barbosa A, Sousa L, Nolan M, Figueiredo D. Effects of person-centered care approaches to dementia care on staff: a systematic review. Am J Alzheimers Dis Other Demen. Epub 2014 Jan 20.

18. Brownie S, Nancarrow S. Effects of person-centered care on residents and staff in aged-care facilities: a systematic review. Clin Interv Aging. 2013;8:1-10.

19. Kane RA, Lum TY, Cutler LJ, Degenholtz HB, Yu TC. Resident outcomes in small-house nursing homes: a longitudinal evaluation of the initial Green House program. J Am Geriatr Soc. 2007;55:832-839.

20. Díaz-Veiga P, Sancho M, Garcia A, et al. Efectos del Modelo de Atención Centrado en la Persona en la calidad de vida de personas con deterioro cognitivo residentes en Centros Gerontológicos. [Effects of person-centered care approaches on the quality of life of geriatric residents with cognitive impairment]. Rev Esp Geriatr Gerontol. 2014;49(6):266-271.

21. Knight C, Haslam SA, Haslam C. In home or at home? How collective decision making in a new care facility enhances social interaction and wellbeing amongst older adults. Ageing Soc. 2010;30:1393-1418.

22. Campbell DT, Stanley JC. Experimental and Quasi-experimental Design for Research. Chicago: Rand MacNally \& Company; 1966.

23. Fernández-Ballesteros R. Sistema de Evaluación de Residencias de Ancianos, SERA. [Assessment System for Older Adults Residences]. Madrid: INSERSO; 1996.

24. Moos R, Lemke S. Multiphasic Environmental Assessment Procedure (MEAP). California: LA, Sage Pub; 1996.
25. Fleiss JL. Statistical Methods for Rates and Proportions. 2nd ed. New York: Wiley; 1981.

26. Hayes AF. Introduction to Mediation, Moderation, and Conditional Process Analysis. New York: The Guilford Press; 2013.

27. Edwards JR, Lambert LS. Methods for integrating moderation and mediation: a general analytical framework using moderated path analysis. Psychol Methods. 2007;12:1-22.

28. Cuddy AJC, Norton MI, Fiske ST. This old stereotype: the pervasiveness and persistence of the elderly stereotype. J Soc Issues. 2005;61: 265-283.

29. Fernández-Ballesteros R, Bustillos A, Santacreu M, et al. Assessing ageing stereotypes. 12th European Conference of Psychological Assessment. July: San Sebastian, 2013.

30. Fernández-Ballesteros R, Izal M, Hernández JM, et al. Evaluation of residential programs for the elderly in Spain and the United States. Eval Pract. 1991;12:159-164.

31. Biggs M. Self-fulfilling prophecies. In: Hedstrom P, Bearman P, editors. The Oxford Dictionary of Analytical Sociology. New York: Oxford University Press; 2009:294-315.

32. Fernández-Ballesteros R, Caprara G, Schettini R, et al. Effects of university programs for older adults. Changes in cultural and group stereotypes, self-perception of aging, and emotional balance. Educ Gerontol. 2013;39:119-131.
Clinical Interventions in Aging

\section{Publish your work in this journal}

Clinical Interventions in Aging is an international, peer-reviewed journal focusing on evidence-based reports on the value or lack thereof of treatments intended to prevent or delay the onset of maladaptive correlates of aging in human beings. This journal is indexed on PubMed Central, MedLine,

\section{Dovepress}

CAS, Scopus and the Elsevier Bibliographic databases. The manuscript management system is completely online and includes a very quick and fair peer-review system, which is all easy to use. Visit http://www.dovepress. com/testimonials.php to read real quotes from published authors. 